\title{
Carbon monoxide differentially inhibits TLR signaling pathways by regulating ROS- induced trafficking of TLRs to lipid rafts
}

\author{
Kiichi Nakahira, ${ }^{1}$ Hong Pyo Kim,${ }^{1}$ Xue Hui Geng, ${ }^{2}$ Atsunori Nakao, ${ }^{3}$ \\ Xue Wang, ${ }^{1}$ Noriko Murase, ${ }^{3}$ Peter F. Drain, ${ }^{2}$ Xiaomei Wang, ${ }^{1}$ \\ Madhu Sasidhar, ${ }^{4}$ Elizabeth G. Nabel, ${ }^{5}$ Toru Takahashi, ${ }^{6}$ \\ Nicholas W. Lukacs, ${ }^{7}$ Stefan W. Ryter, ${ }^{1}$ Kiyoshi Morita, ${ }^{6}$ \\ and Augustine M.K. Choi ${ }^{1}$
}

\begin{abstract}
'Division of Pulmonary, Allergy and Critical Care Medicine, ${ }^{2}$ Department of Cell Biology and Physiology, and ${ }^{3}$ Department of Surgery, University of Pittsburgh School of Medicine, Pittsburgh, PA 15213

${ }^{4}$ Section of Pulmonary and Critical Care Medicine, Yale University School of Medicine, New Haven, CT 06520

${ }^{5}$ National Heart, Lung, and Blood Institute, National Institutes of Health (NIH), Bethesda, MD 20892

${ }^{6}$ Department of Anesthesiology and Resuscitology, Okayama University Medical School, Okayama-shi 700-8558, Japan
\end{abstract}

7Department of Pathology, University of Michigan Medical School, Ann Arbor, Ml 48109

\section{CORRESPONDENCE \\ Augustine M.K. Choi: \\ choiam@upmc.edu}

Abbreviations used: $\mathrm{CO}$, carbon monoxide; CTx, cholera toxin; DPI, diphenylene iodonium;

GM1, glycosphingolipid 1; $\mathrm{HO}$

heme oxygenase; IP-10, IFN-

$\gamma$-inducible protein 10; IRF-3,

IFN regulatory factor 3; MAPK, mitogen-activated protein

kinase; $\mathrm{M} \beta \mathrm{CD}$, methyl- $\beta$ -

cyclodextrin; MDC, monodan-

sylcadaverine; NAC,

$\mathrm{N}$-acetyl-L-cysteine; PAMP,

pathogen-associated molecular

pattern; poly(I:C), polyinosinepolycytidylic acid; RANTES,

regulated upon activation, normal $\mathrm{T}$ expressed, and presum-

ably secreted; ROS, reactive oxygen species; TLR, Toll-like receptor; TRAF, TNF receptorassociated factor; TRIF, TIR

domain-containing adaptorinducing IFN- $\beta$.

\begin{abstract}
Carbon monoxide (CO), a byproduct of heme catabolism by heme oxygenase (HO), confers potent antiinflammatory effects. Here we demonstrate that $\mathrm{CO}$ derived from $\mathrm{HO}-1$ inhibited Toll-like receptor (TLR) 2, 4, 5, and 9 signaling, but not TLR3-dependent signaling, in macrophages. Ligand-mediated receptor trafficking to lipid rafts represents an early event in signal initiation of immune cells. Trafficking of TLR4 to lipid rafts in response to LPS was reactive oxygen species (ROS) dependent because it was inhibited by diphenylene iodonium, an inhibitor of NADPH oxidase, and in gp9 $1^{\text {phox }}$-deficient macrophages. CO selectively inhibited ligand-induced recruitment of TLR4 to lipid rafts, which was also associated with the inhibition of ligand-induced ROS production in macrophages. TLR3 did not translocate to lipid rafts by polyinosine-polycytidylic acid (poly(I:C)). CO had no effect on poly(I:C)induced ROS production and TLR3 signaling. The inhibitory effect of CO on TLR-induced cytokine production was abolished in gp9 1 $^{\text {phox }}$-deficient macrophages, also indicating a role for NADPH oxidase. CO attenuated LPS-induced NADPH oxidase activity in vitro, potentially by binding to gp $91^{\text {phox. Thus, }} \mathrm{CO}$ negatively controlled TLR signaling pathways by inhibiting translocation of TLR to lipid rafts through suppression of NADPH oxidase-dependent ROS generation.
\end{abstract}

Carbon monoxide (CO) arises physiologically in cells during the oxidative catabolism of heme by heme oxygenase (HO) enzymes (1). HO-1, an inducible isoform of $\mathrm{HO}$, provides a protective response to injury associated with proapoptotic stimuli or inflammation (1). Both mice and humans deficient in HO-1 expression have a phenotype of an increased inflammatory state (2-4). We have previously described that CO can not only suppress LPS-induced proinflammatory cytokine production, but also decrease mortality in a mouse model of sepsis $(5,6)$. We further showed that these antiinflammatory

K. Nakahira and H.P. Kim contributed equally to this work. The online version of this article contains supplemental material. effects of $\mathrm{CO}$ are mediated by the mitogenactivated protein kinase (MAPK) pathway $(5,6)$. However, nothing is known regarding the effect of $\mathrm{CO}$ on upstream Toll-like receptor (TLR) signaling pathways.

TLRs are innate receptors critically involved in the initial phase of microbial detection (7). The recognition of distinct pathogenassociated molecular patterns (PAMPs) by TLRs activates signaling pathways that induce the expression of proinflammatory genes (7). Although the immune system of TLRs contributes to host defense, the TLRs have also been implicated in the pathogenesis of inflammatory human diseases $(7,8)$. To avoid inappropriate hyperresponses of the immune system, 
the intensity and duration of TLR signaling require tight regulation $(7,8)$.

Plasma membranes of cells contain specialized microdomains called lipid rafts, which exert an important function in signal transduction of the immune system (9, 10). Several studies have demonstrated that membrane rafts play a key role in $\mathrm{T}$ cell and B cell activation by accumulating essential signaling molecules $(9,10)$. Recently, it has been apparent that lipid rafts are required not only for adaptive immune responses, but also for innate immune responses (10). TLR2 or TLR 4 is recruited to membrane rafts by ligand or bacteria treatment $(11,12)$. Disruption of lipid rafts by methyl- $\beta$ cyclodextrin (M $\beta C D)$ or nystatin inhibits proinflammatory cytokine production $(11,12)$.

Here we investigated how $\mathrm{CO}$ affects TLR signaling pathways in macrophages. CO negatively regulated TLR2, 4, 5, and 9 signaling pathways, but not TLR3. Although TLR 4 translocated to lipid rafts after LPS stimulation and CO suppressed its recruitment, TLR3 did not translocate to lipid rafts and remained in the intracellular compartment after polyinosine-polycytidylic acid (poly(I:C)) stimulation in the absence or presence of CO. We demonstrated differential trafficking patterns of TLRs to lipid rafts. CO inhibits trafficking of not only TLRs but also of adaptor molecules, resulting in the suppression of downstream signaling pathways. Furthermore, we show that NADPH oxidase-dependent reactive oxygen species (ROS) production is involved in the translocation of TLR 4 to lipid rafts by LPS, and that $\mathrm{CO}$ inhibits that trafficking by regulating NADPH oxidase activity.

\section{RESULTS}

\section{Increased expression of TNF- $\alpha$ in $\mathrm{HO}-1^{-I-}$ null mice}

Because HO-1 is a well-known cytoprotective protein induced by inflammation or oxidative stress (1), we evaluated the physiological properties of HO-1 in vivo by using $\mathrm{HO}-1$ null $\left(\mathrm{HO}-1^{-/-}\right)$mice. We stained kidneys and livers for $\mathrm{CI}$ : A3-1 as an indicator of mouse monocytes or macrophages, and for TNF- $\alpha$ by immunohistochemistry under basal untreated conditions. We observed significant infiltration of macrophages and TNF- $\alpha$ expression around the convoluted tubules in the cortex of the kidney from $\mathrm{HO}-1^{-/-}$mice (Fig. 1, $A$ and $\mathrm{B}$ ). In contrast, immunohistochemical staining for macrophages and TNF- $\alpha$ was negligible in the kidney of wild-type $\left(\mathrm{HO}-1^{+/+}\right)$mice (Fig. 1, C and D). In the livers from $\mathrm{HO}-1^{-1-}$ mice (Fig. $1 \mathrm{E}$ ), marked accumulation of macrophages was observed in the portal vein accompanied with cellular infiltration in the interlobular septum as compared with in the liver from $\mathrm{HO}-1^{+/+}$mice (Fig. $1 \mathrm{G}$ ). Kupffer cells, which also can be stained by the CI:A3-1 marker, are likely to represent the increased staining observed in the sinusoid of the liver from $\mathrm{HO}-1^{-/-}$mice relative to that from HO- $1^{+/+}$mice (Fig. 1, E and G). TNF- $\alpha$ expression was also markedly induced, consistent with localization of the macrophages in the liver from $\mathrm{HO}-1^{-/-}$mice (Fig. $1 \mathrm{~F}$ ), as compared with liver from $\mathrm{HO}-1^{+/+}$mice (Fig. $1 \mathrm{H}$ ). In addition, increased staining for macrophages and expression of TNF- $\alpha$ was observed in the intestines from $\mathrm{HO}-1^{-/-}$ mice compared with control mice (unpublished data). These results suggest that systemic inflammation is chronically increased in the $\mathrm{HO}-1^{-/-}$mice $(2-4)$, consistent with the known antiinflammatory properties of $\mathrm{HO}-1$ and the involvement of HO-1 in regulating the functions of monocyte/macrophages $(13,14)$.

\section{Negative regulation of $\mathrm{HO}-1$ in TLR signaling is mediated by $\mathrm{CO}$}

HO-1 is significantly induced by LPS (a ligand for TLR4) stimulation and has been shown to dampen the inflammatory effects of LPS-treated models $(5,13,14)$. Therefore, we examined whether $\mathrm{HO}-1$ could modulate the immune response in various TLR signaling pathways. HO-1-overexpressing
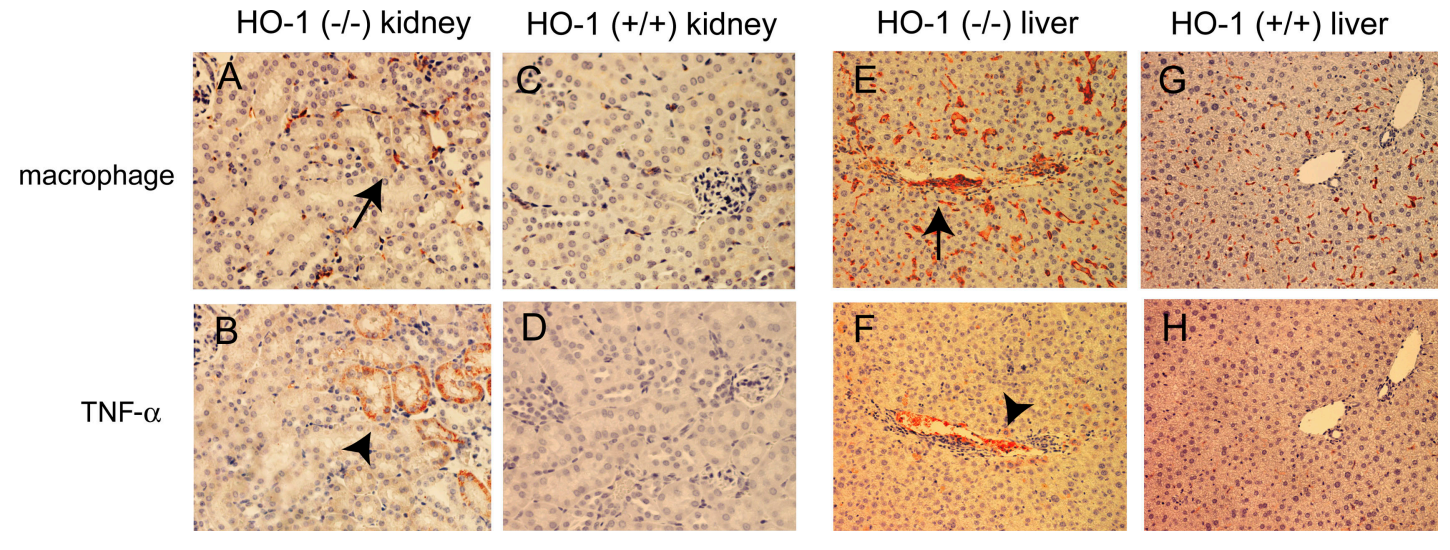

Figure 1. Expression of TNF- $\alpha$ and macrophages in the kidneys and livers of H0-1 null mice. Livers and kidneys were harvested from $\mathrm{HO}-1$ null mice $\left(\mathrm{HO}-1^{-1-} ; n=3\right)$ or wild-type mice $\left(\mathrm{HO}-1^{+1+} ; n=3\right)$ under untreated conditions, and tissue sections were immunostained with anti-TNF- $\alpha$ or anti-Cl:A3-1 for the detection of macrophages/ monocytes. Representative light microscopic views are shown. Arrows and arrowheads indicate the influx of macrophages and TNF- $\alpha$ expression, respectively. 
A
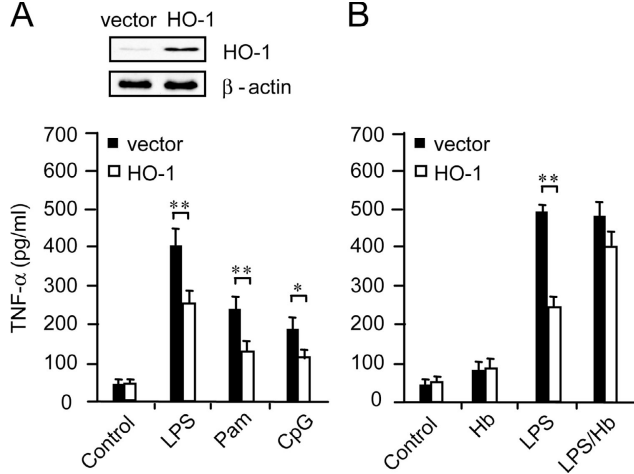

Figure 2. Effect of HO-1 overexpression on TLR ligand-induced TNF- $\alpha$ production in macrophages. (A) RAW 264.7 cells overexpressing HO-1 or control cells were treated with $100 \mathrm{ng} / \mathrm{ml} \mathrm{LPS}, 100 \mathrm{ng} / \mathrm{ml}$ Pam, or $1 \mu \mathrm{M} \mathrm{CpG}$ for $1 \mathrm{~h}$, and culture media were collected for TNF- $\alpha$ measurement. (B) The cells were pretreated with $5 \mu \mathrm{M}$ of hemoglobin $(\mathrm{Hb})$ for $30 \mathrm{~min}$ and stimulated with LPS for $1 \mathrm{~h}$. TNF- $\alpha$ in culture media was measured by ELISA. * $\mathrm{P}<0.05$ and ${ }^{* *}, \mathrm{P}<0.01$ versus HO-1-overexpressing cells.

RAW 264.7 macrophages produced significantly less TNF- $\alpha$ than the control cells in response to LPS, Pam ${ }_{3}$ CSK4 (a ligand for TLR2), and CpG (a ligand for TLR9) (Fig. 2 A; references 5 and 6). However, when the HO-1-overexpressing cells were treated with LPS and hemoglobin, a scavenger of CO (14), the cells failed to inhibit LPS-induced TNF- $\alpha$ production (Fig. $2 \mathrm{~B}$ ). These data suggest that the antiinflammatory effect of HO-1 on TLR signaling pathways in macrophages is mediated primarily by CO (5).

\section{CO differentially inhibits TLR signaling}

Because HO-1 inhibited TLR2, 4, and 9 ligand-induced TNF- $\alpha$ production (Fig. $2 \mathrm{~A}$ ), and $\mathrm{CO}$ as a byproduct of heme catabolism by HO-1 was critically involved with the antiinflammatory effect of HO-1 (Fig. 2 B), we next investigated the effect of CO on various TLR ligand-induced cytokine production in RAW 264.7 cells (TLR ligands; TLR2, peptidoglycan or $\mathrm{Pam}_{3}$ CSK4 [Pam]; TLR3, double-stranded RNA poly(I:C); TLR4, LPS; TLR5, flagellin [Fla]; and TLR9, CpG). CO exposure significantly suppressed TLR2, 4, 5, and 9 ligand-induced TNF- $\alpha$ production (Fig. 3 A), which is similar to the effect of HO-1 observed in Fig. 2 A. However, CO did not affect poly(I:C)-induced TNF- $\alpha$ production (Fig. 3 A). As previously described, the effect of $\mathrm{CO}$ on LPS-induced cytokine production was dose dependent over a range of 50-500 ppm $(5,6)$; however, cytokine production by poly(I:C) was not affected by $\mathrm{CO}$ exposure at any of the doses (Fig. $3 \mathrm{~B}$ ). To further confirm the effect of $\mathrm{CO}$ on macrophages, mouse peritoneal macrophages were stimulated with the TLR ligands in the presence or absence of $\mathrm{CO}$. The effect of $\mathrm{CO}$ on $\mathrm{TNF}-\alpha$ production in the mouse peritoneal macrophages was consistent with that observed in RAW 264.7 macrophages (Fig. 3, A and C). Because poly (I:C) is recognized not only by TLR3 but also by the helicase domain of MDA5 or RIG-I (15), we examined the relative role of TLR3 in poly(I:C)-induced cytokine production by using peritoneal macrophages from TLR3-deficient mice $\left(t \operatorname{tr} 3^{-/-}\right)$. Consistent with previous results (16), poly(I:C)induced $\mathrm{TNF}-\alpha$ production in $t r 3^{-1-}$ macrophages was reduced to nearly background levels, relative to the poly (I:C)-induced TNF- $\alpha$ production observed in wild-type
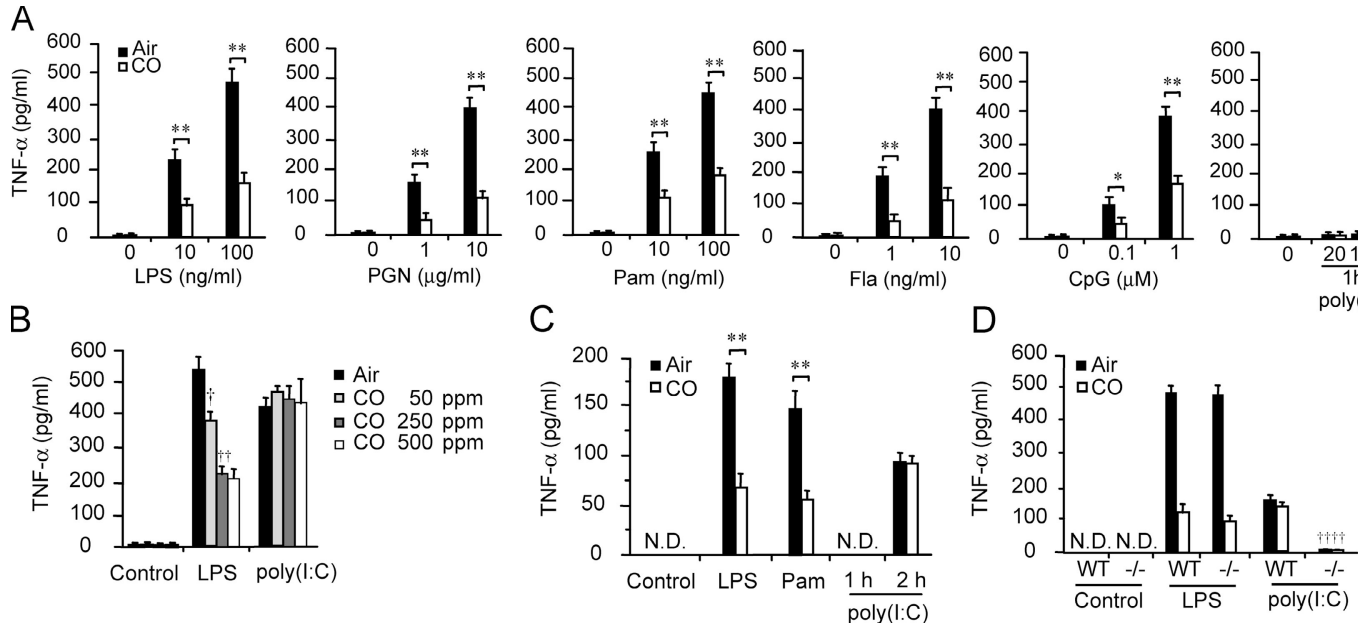

Figure 3. Effect of $\mathrm{CO}$ on TLR ligand-induced TNF- $\alpha$ production in macrophages. (A) RAW 264.7 cells were pretreated with 250 ppm CO for $2 \mathrm{~h}$, followed by stimulation with the indicated concentrations of TLR ligands. Cell media were collected 1 or $2 \mathrm{~h}$ after the ligand treatment and TNF- $\alpha$ was measured by ELISA. ${ }^{*}, \mathrm{P}<0.05$ and ${ }^{* *}, \mathrm{P}<0.01$ versus $\mathrm{CO}$ treated cells. (B) Cells were treated with various concentrations of $\mathrm{CO}$ and stimulated with $100 \mathrm{ng} / \mathrm{ml}$ LPS or $20 \mu \mathrm{g} / \mathrm{ml}$ poly $(\mathrm{l}: \mathrm{C})$ for 1 or $2 \mathrm{~h}$. TNF- $\alpha$ in the culture media was measured.,$+ P<0.05$ and,$++ P<0.01$ versus
LPS-treated control cells. (C) Mouse peritoneal macrophages were pretreated with $250 \mathrm{ppm}$ CO for $2 \mathrm{~h}$, followed by stimulation with TLR ligands for 1 or $2 \mathrm{~h}$. Culture media were collected and TNF- $\alpha$ was measured by ELISA. ${ }^{* *}, \mathrm{P}<0.01$ versus $\mathrm{C} 0$-treated cells. (D) Mouse peritoneal macrophages from wild-type (WT) mice or TLR3-deficient mice $(-1-)$ were stimulated with $100 \mathrm{ng} / \mathrm{ml}$ LPS or $20 \mu \mathrm{g} / \mathrm{ml}$ poly $(\mathrm{l}: \mathrm{C})$ for 1 or $2 \mathrm{~h}$, and TNF- $\alpha$ in culture media was measured by ELISA.,$++ \mathrm{P}<0.01$ versus poly(l:C)-stimulated wild-type cells. 


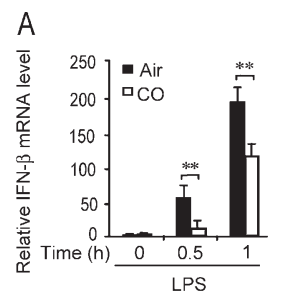

B
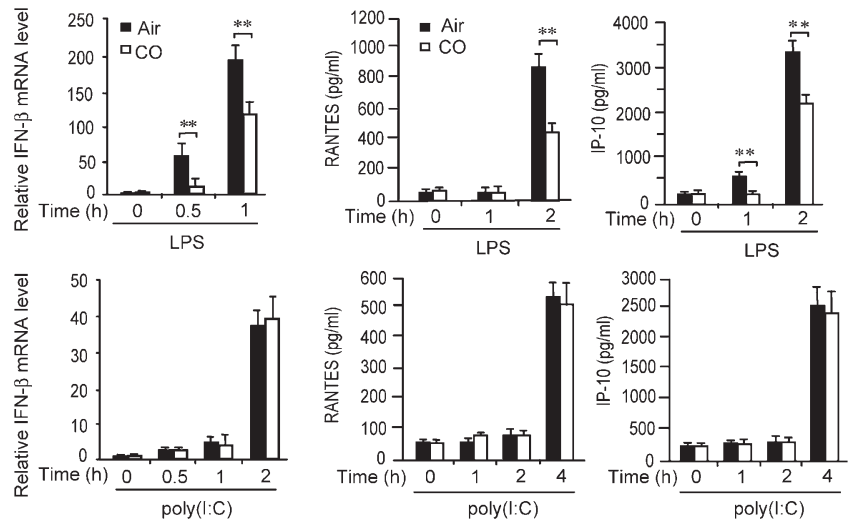

Figure 4. Effect of $\mathrm{CO}$ on IRF-3-related cytokine production in macrophages. (A) RAW 264.7 cells were treated with $100 \mathrm{ng} / \mathrm{ml}$ LPS or $20 \mu \mathrm{g} / \mathrm{ml}$ poly $(I: C)$ in the absence or presence of $\mathrm{CO}$, and their IFN- $\beta$ mRNA expression at the indicated time points was analyzed by real-time RT-PCR. (B) IP-10 and RANTES production in culture media was analyzed by ELISA. ${ }^{*}, P<0.01$ versus $C 0$-treated cells.

macrophages (Fig. 3 D). On the other hand, as expected, the levels of LPS-induced TNF- $\alpha$ production were comparable in wild-type and $t l r 3^{-1-}$ macrophages (Fig. $3 \mathrm{D}$ ). Activation of both TLR 3 and TLR 4 signaling cascades induces IFN- $\beta$ through the activation of IFN regulatory factor 3 (IRF-3), leading to the production of IFN-inducible gene products, such as IFN- $\boldsymbol{\gamma}$-inducible protein 10 (IP-10) and the regulated upon activation, normal $\mathrm{T}$ expressed, and presumably secreted protein (RANTES; references 17 and 18). Although CO significantly inhibited LPS-induced IFN- $\beta$ gene expression and the production of IP-10 and RANTES, the induction of these cytokines by poly(I:C) was not inhibited by $\mathrm{CO}$ (Fig. 4, A and B).

CO modulates transcription factor activation by TLR ligands, but not by poly(l:C)

Both NF-kB and IRF-3 are key transcription factors activated in TLR 3 and TLR4 signaling pathways $(7,16)$. Because CO inhibited the TLR ligand-induced (except TLR3) cytokine production, we next examined the effect of $\mathrm{CO}$ on the ligand-induced activation of NF- $\mathrm{KB}$ and IRF-3. CO inhibited LPS-induced NF- $\kappa B$ activation as described previously (19), and Pam-, Fla-, and CpG-induced NF- $\mathrm{\kappa B}$ activation was also significantly suppressed by CO (Fig. 5, A and B). Translocation of IRF-3 to the nuclear fraction increased after LPS treatment (18), and CO significantly suppressed its translocation (Fig. 5 C). However, CO had no effect on poly(I:C)-induced NF-кB activation and translocation of IRF-3 (Fig. 5). Consistent with the effect of CO on TLR ligand-induced cytokine production (Figs. 3 and 4), CO inhibited the activation of transcriptional factors by LPS, but not by poly(I:C) (Fig. 5). These results indicate that CO differentially regulates TLR signaling pathways.
A

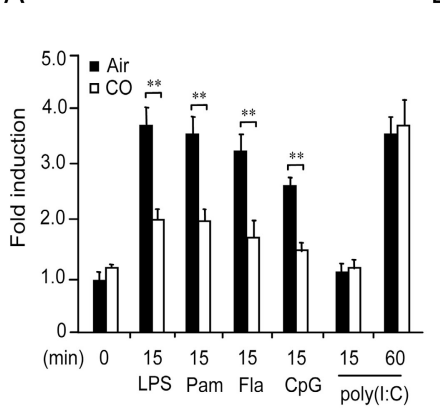

B Control LPS Pam poly(1:C)

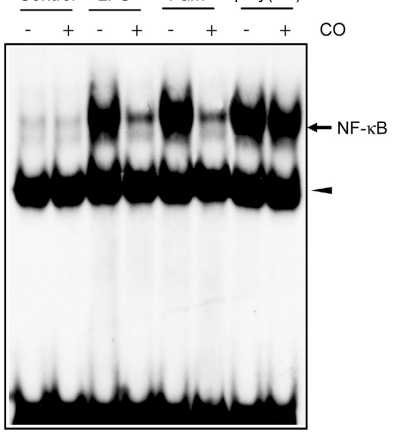

C

LPS

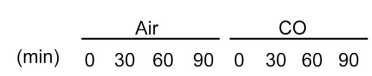

IRF-3

USF2 $---$

SF $2-\cdots-\cdots$

poly(l:C)

IRF-3
USF2

Figure 5. CO inhibits activation of NF- $\mathrm{KB}$ and nuclear translocation of IRF-3 by LPS, but not by poly(I:C). RAW 264.7 cells were stimulated with $100 \mathrm{ng} / \mathrm{ml}$ LPS, $100 \mathrm{ng} / \mathrm{ml} \mathrm{Pam}, 10 \mathrm{ng} / \mathrm{ml} \mathrm{Fla,} 1 \mu \mathrm{M} \mathrm{CpG}$, and $20 \mu \mathrm{g} / \mathrm{ml}$ poly $(1: C)$ in the presence or absence of $\mathrm{CO}$. Nuclear protein was extracted for NF- $\mathrm{KB}$ activation assay or Western blot analysis. (A) NF- $\mathrm{KB}$ (p65) activation was analyzed by ELISA-based kits. ${ }^{* *}, \mathrm{P}<0.01$ versus $\mathrm{CO}$-treated cells. (B) NF-KB was analyzed by electrophoretic mobility shift assay. Protein-DNA complexes are shown. Arrowhead indicates nonspecific bands. (C) Nuclear extract was analyzed by immunoblotting for IRF-3 nuclear translocation, followed by stripping and reprobing for upstream stimulatory factor 2 (USF2).

\section{CO suppresses the interactions of TLR4 and adaptor molecules}

With the exception of TLR3, all the TLRs interact with an adaptor protein, MyD88 (7). TLR3 uses only the adaptor molecule TIR domain-containing adaptor-inducing IFN- $\beta$ (TRIF) to activate IRF-3, and TLR4 also activates IRF-3 through TRIF. To investigate the effect of CO on upstream events in TLR signaling pathways, we assessed the effect of $\mathrm{CO}$ on interactions of TLRs and adaptor molecules that are subsequently induced after ligand binding to $\operatorname{TLR}(7,8)$. We observed increased interaction not only between TLR 4 and MyD88 but also between TLR 4 and TRIF at 5 min after LPS treatment (20); however, CO markedly attenuated both interactions (Fig. 6 A). Although poly(I:C) treatment also increased the interaction of TLR 3 and TRIF, CO did not suppress the TLR 3 and TRIF interaction (Fig. 6 B). These experiments support the notion that the negative regulation of $\mathrm{CO}$ on TLR signaling pathways is likely to be dependent not on adaptor proteins, but on the specificity of TLRs.

\section{CO regulates translocation of TLRs to lipid rafts}

Membrane rafts are involved with TLR signaling, including the activation of NF- $\mathrm{KB}$ and cytokine production $(11,21)$. To further address the involvement of lipid rafts on TLR signaling pathways and the potential role of $\mathrm{CO}$ on the membrane rafts, cells were stimulated with LPS or poly(I:C) 


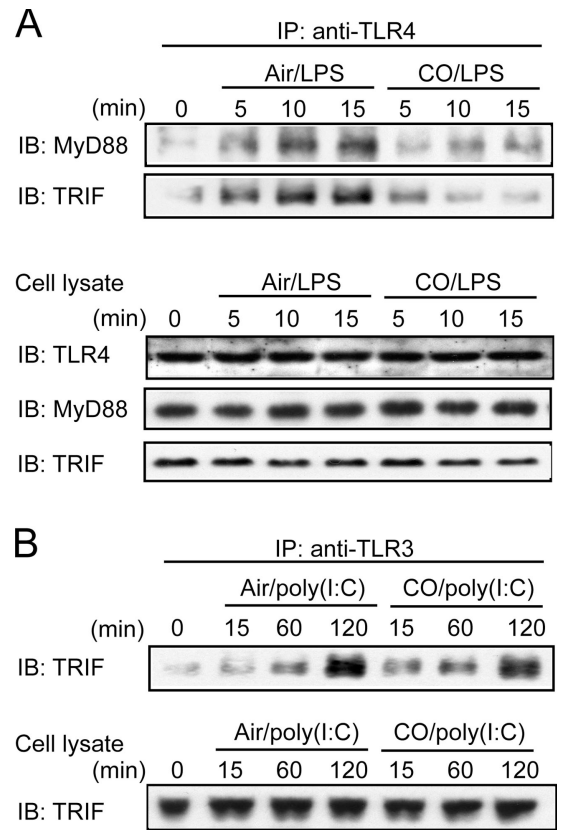

Figure 6. Effect of $\mathrm{CO}$ on interactions of TLRs and adaptor molecules. RAW 264.7 cells were treated with $100 \mathrm{ng} / \mathrm{ml}$ LPS or $20 \mu \mathrm{g} / \mathrm{ml}$ poly $(I: C)$ in the absence or presence of $\mathrm{CO}$. (A) Interaction between TLR4 and MyD88 or TLR4 and TRIF was analyzed with immunoprecipitation and immunoblotting. Expression of TLR4, MyD88, and TRIF was analyzed by immunoblotting using total cell lysates. (B) Interaction of TLR3 and TRIF was analyzed with immunoprecipitation and immunoblotting.

in the presence or absence of $\mathrm{CO}$ and incubated with FITCcholera toxin (CTx). CTx specifically binds to the glycosphingolipid 1 (GM1), which is enriched in lipid rafts (22, 23). In the resting RAW 264.7 cells, the distribution of GM1 on the plasma membrane was quite homogeneous and TLR4 localized, in a diffuse manner, both in the membrane and intracellular compartment (Fig. 7 A; reference 21). After LPS treatment, a large fraction of TLR 4 translocated to the plasma membrane, and colocalization of TLR4 and GM1 was also observed (Fig. 7 A). In CO-treated cells, the LPSinduced translocation of TLR 4 to the membrane rafts was significantly inhibited (Fig. 7 A). In contrast, TLR3 localized in the intracellular compartment in the resting cells (Fig. 7 A), which is consistent with previous results $(17,24)$, and remained unchanged after poly(I:C) stimulation, even when $\mathrm{CO}$ was added (Fig. 7 A). The localization of TLR4 and TLR 3 did not change in the cells treated with $\mathrm{CO}$ alone (unpublished data). Next, cells were incubated with FITCCTx and cross-linked with anti-CTx. CTx specifically binds to the GM, and GM1-CTx can be crossed-linked to membrane patches with anti-CTx $(22,23,25)$. These membrane patches have properties that are similar to those of biochemically isolated rafts $(22,23,25)$. Without anti-CTx crosslinking, distribution of GM1 on the plasma membrane was homogeneous and TLR 4 was expressed in a diffuse manner (Fig. S1 A, available at http://www.jem.org/cgi/content/ full/jem.20060845/DC1). After the anti-CTx cross-linking at $37^{\circ} \mathrm{C}$, a large part of GM1 translocated to a crescent-shaped patched area in the plasma membrane and a large fraction of TLR4 also translocated to the same area. Colocalization of TLR4 and GM1 was observed (Fig. S1 A). In contrast, TLR 3 remained unchanged in the cytosolic fraction, not in the crescent-shaped patched area, after the cross-linking at $37^{\circ} \mathrm{C}$ (Fig. S1 B). To further investigate whether CO modulates the translocation of TLR 4 and its adaptor molecules to lipid rafts, we isolated raft fractions and examined the translocation of the proteins involved in TLR signaling by immunoblotting. Flotillin-1, constitutively expressed in lipid rafts (26), localized in fractions 3 and 4. LPS or CO treatment had no effect on its abundance among the sucrose density fractions (Fig. 7 B). Most of GM1 localized in the same fractions (Fig. 7 B) and no alteration of the distribution was observed by LPS or CO treatment (unpublished data; references 11 and 27). TLR4 and its adaptor molecules (MyD88 and TRIF), as well as MD-2, IL-1 receptor-associated kinase, TNF receptor-associated factor (TRAF)-6, p65, and IкB- $\alpha$, rapidly translocated to lipid rafts after LPS stimulation $(11,27)$, whereas TRAF-2 was not translocated (Fig. $7 \mathrm{~B})$. In contrast, CO significantly inhibited the LPS-induced recruitment of TLR 4 and other signaling molecules to lipid rafts (Fig. 7 B). The distribution of TLR 4 was not affected by $\mathrm{CO}$ treatment alone (Fig. 7 B). Consistent with other data (11), CD-14 was constitutively expressed mainly in lipid rafts of resting cells and its expression was unaffected by LPS or CO treatment (Fig. 7 B). To confirm the differential localization and translocation patterns of TLRs, TLR3, 4, and 9 were immunoprecipitated with each antibody and immunoblotted with the same antibody using Triton X-100 soluble and insoluble raft fractions. After the ligand stimulation, TLR4 and TLR 9 translocated to the rafts fraction, whereas TLR 3 did not (Fig. 7 C). In addition, the adaptor protein TRIF interacted with TLR 4 in the rafts fraction by LPS stimulation, but not with TLR3 by poly(I:C) (Fig. 7 C). These results confirm the differential translocation of TLRs to lipid rafts by ligand stimulation and agree with our immunofluorescence data (Fig. $7 \mathrm{~A}$ and Fig. S1). To examine the role of lipid rafts as a platform of ligand-induced TLR activation, we pretreated cells with $\mathrm{M \beta CD}$ and stimulated them with LPS, Pam, or poly(I:C). Although LPS- or Paminduced TNF- $\alpha$ production was significantly reduced by $\mathrm{M} \beta \mathrm{CD}$ treatment, poly(I:C)-induced cytokine production was unaffected (Fig. 7 D; references 11 and 28). In contrast, pretreatment of monodansylcadaverine (MDC), an inhibitor of the clathrin-dependent internalization pathway (29), markedly suppressed TNF- $\alpha$ production by poly(I:C) treatment, but not by LPS or Pam in macrophages (Fig. 7 E). These data suggest that the involvement of lipid rafts in TLR signaling is dependent on the specificity of the TLRs.

\section{Inhibition of ROS generation by CO suppresses trafficking of TLR to rafts}

ROS are known to be critical in intracellular signaling, including the TLR signaling pathway, and the scavenging of ROS 
A
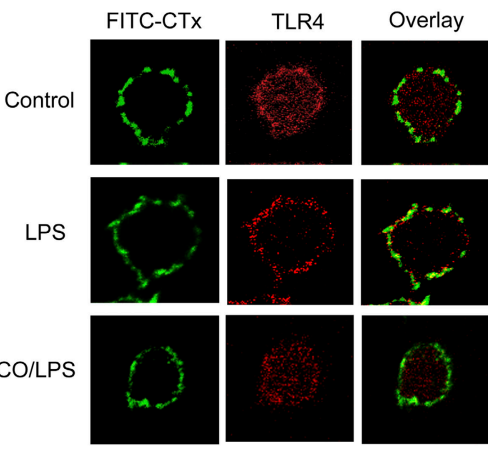

CO/LPS
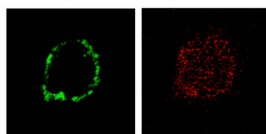

B

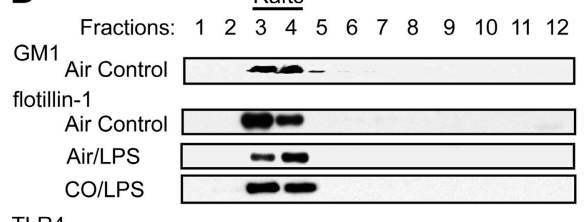

$$
\text { TLR4 }
$$

Air Control CO Control Air/LPS CO/LPS

MD-2

Air Control

Air/LPS CO/LPS

MyD88

Air Control

Air/LPS

CO/LPS

IRAK-1

Air Control

Air/LPS

CO/LPS
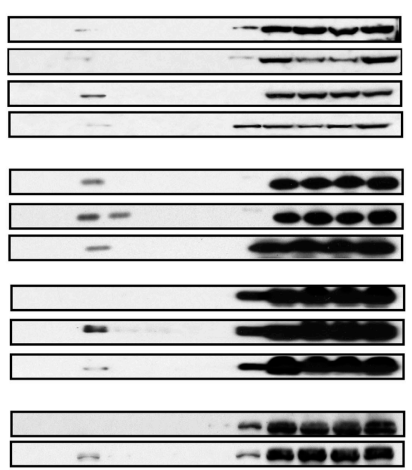

aceserest

C

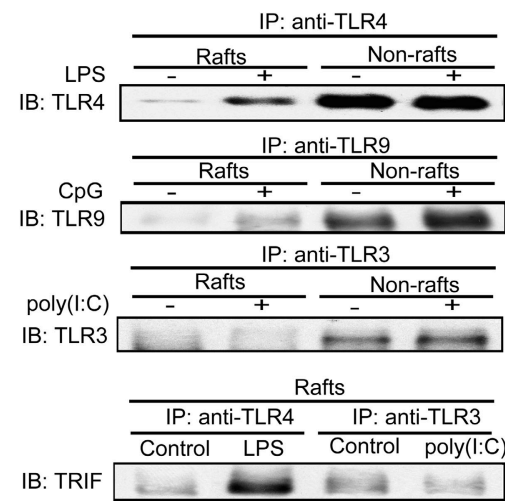

Figure 7. Lipid rafts are involved with TLR signaling, but not TLR3. (A) RAW 264.7 cells were stimulated with LPS or poly(I:C) in the presence or absence of $\mathrm{CO}$ for $1 \mathrm{~h}$, followed by incubation of FITCCTx on ice for $10 \mathrm{~min}$. Cells were analyzed for FITC-CTx-stained GM1 (green) and TLR4 or TLR3 (red) by confocal microscopy. (B) RAW 264.7 cells were stimulated with LPS in the presence or absence of CO for $5 \mathrm{~min}$. Cell lysates were fractionated by sucrose-gradient ultracentrifugation, followed by fractionation to 12 subfractions for immunoblotting with flotillin-1, TLR4, and other signaling proteins. (C) RAW 264.7 cells were treated with $L P S, C p G$, or poly $(I: C)$ for $1 h$, and then lipid raft fractions (fractions 3 and 4) and nonraft fractions (fractions 9-12)
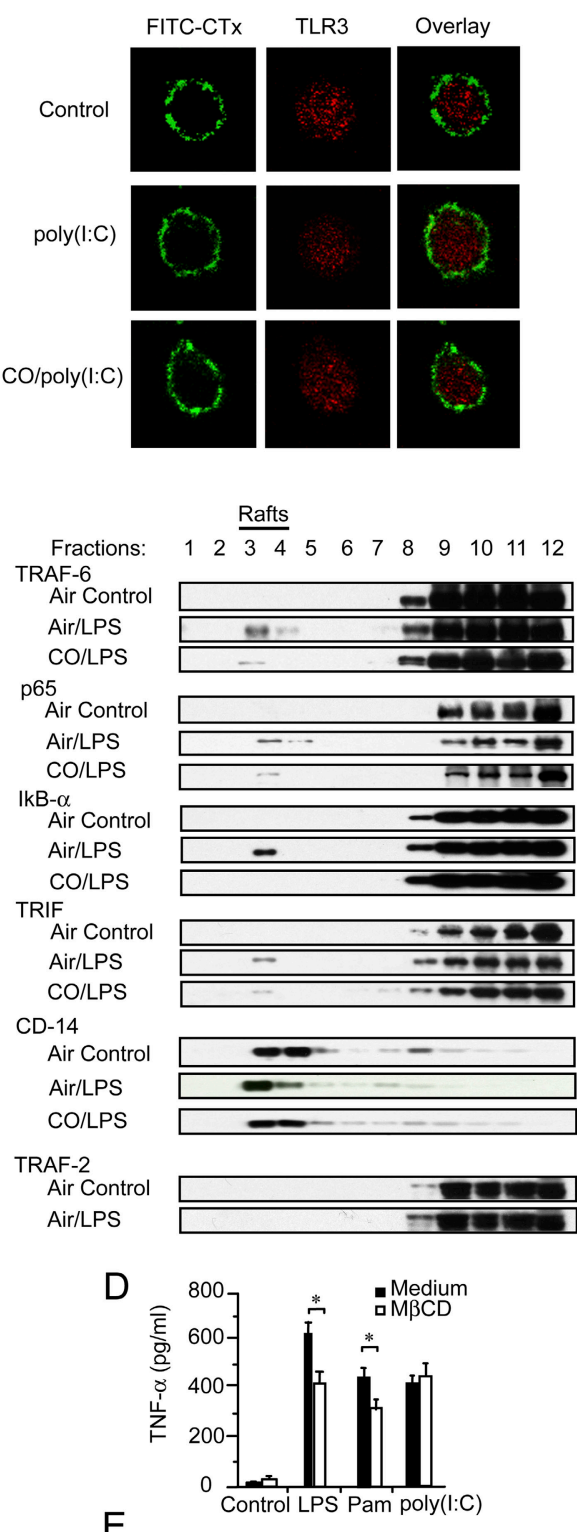

E

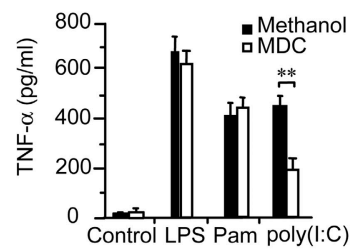

were separated. TLR3, 4, or 9 was immunoprecipitated with anti-TLR3, 4 , or $9 \mathrm{mAb}$ from raft fractions or nonraft fractions, followed by immunoblotting with the anti-TLR3, anti-TLR4, or anti-TRIF mAb. (D) RAW 264.7 cells were pretreated with $15 \mathrm{mM} \mathrm{M \beta CD}$ or medium for 15 min, followed by stimulation with LPS, Pam, or poly(l:C) for 1 or $2 \mathrm{~h}$. Cell media were harvested and TNF- $\alpha$ production was analyzed by ELISA. * ${ }^{*} P<0.05$ versus MBCD-treated cells. (E) RAW 264.7 cells were pretreated with $200 \mu \mathrm{M}$ MDC or methanol as vehicle for $30 \mathrm{~min}$, and then stimulated with LPS, Pam, or poly $(\mathrm{I}: \mathrm{C})$ for 1 or $2 \mathrm{~h}$. TNF- $\alpha$ production in cell media was analyzed by ELISA. ${ }^{*}, \mathrm{P}<0.01$ versus MDCtreated cells. 

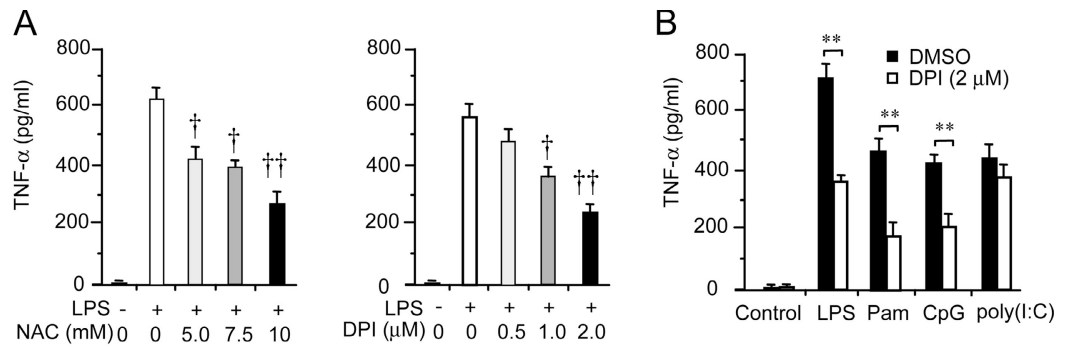
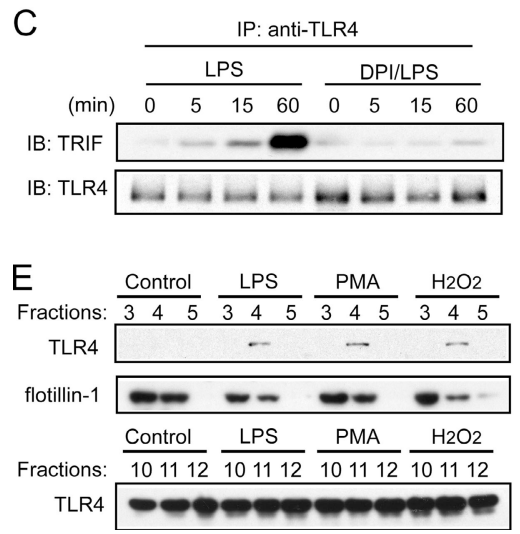

Figure 8. ROS generation is involved with translocation of TLR4 to lipid rafts. (A) RAW 264.7 cells were pretreated with the indicated concentration of NAC or DPI for $30 \mathrm{~min}$, followed by incubation with LPS for $1 \mathrm{~h}$. TNF- $\alpha$ production in cell media was analyzed by ELISA.,$+ \mathrm{P}<0.05$ and $t+, P<0.01$ versus LPS-treated control cells. (B) RAW 264.7 cells were pretreated with $2 \mu \mathrm{M} D P I$, followed by incubation with $L P S, P a m, C p G$, or poly(l:C) for 1 or $2 \mathrm{~h}$. TNF- $\alpha$ production in cell media was analyzed by

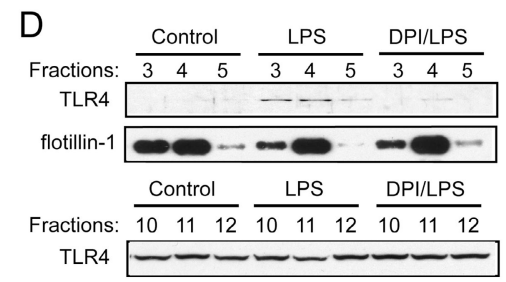

ELISA. ${ }^{*}, \mathrm{P}<0.01$ versus DPI-treated cells. (C) RAW 264.7 cells were pretreated with $2 \mu \mathrm{M}$ DPI or DMSO as vehicle for $30 \mathrm{~min}$, followed by incubation with $100 \mathrm{ng} / \mathrm{ml}$ LPS. Interaction between TLR4 and TRIF was analyzed with immunoprecipitation assay. (D and E) RAW 264.7 cells were pretreated with $2 \mu \mathrm{M}$ DPI for $30 \mathrm{~min}$, followed by incubation with $100 \mathrm{ng} / \mathrm{ml}$ LPS, $100 \mu \mathrm{M} \mathrm{H}_{2} \mathrm{O}_{2}$, or $1 \mu \mathrm{M}$ PMA for $1 \mathrm{~h}$. Cell lysates were fractionated to 12 subfractions, followed by immunoblotting for TLR4 and flotillin-1. or the inhibition of NADPH oxidase suppresses LPS-induced cytokine production $(30,31)$. To examine if ROS are involved with the TLR signaling pathway and trafficking of TLR to lipid rafts, RAW 264.7 cells were pretreated with the antioxidant $N$-acetyl-L-cysteine (NAC) or a NADPH oxidase inhibitor, diphenylene iodonium (DPI), for $30 \mathrm{~min}$, followed by incubation with TLR ligands. NAC and DPI suppressed LPS-induced TNF- $\alpha$ production in a dose-dependent manner (Fig. $8 \mathrm{~A}$ ), and DPI significantly suppressed TNF- $\alpha$ production induced by LPS, Pam, and $\mathrm{CpG}$, but not by poly(I:C) treatment (Fig. 8 B). DPI also inhibited LPS-induced interaction of TRIF and TLR 4 (Fig. 8 C). In addition, we observed that the LPS-induced translocation of TLR4 to lipid rafts was inhibited by DPI treatment (Fig. 8 D). These results indicate that inhibition of NAPDH oxidase suppresses the TLR signaling pathway by modulating events upstream of the pathway. Furthermore, cellular stimulation with $\mathrm{H}_{2} \mathrm{O}_{2}$ and PMA also recruit TLR 4 to lipid rafts (Fig. $8 \mathrm{E}$ ), which is consistent with previously reported results (32). To investigate the involvement of CO on TLR ligand-induced ROS generation, we detected TLR ligand-induced ROS production by using a fluorescence probe. CO significantly suppressed not only LPSbut also Pam-induced ROS production (Fig. 9 A). However, $\mathrm{CO}$ failed to inhibit poly(I:C)-induced ROS production in macrophages (Fig. 9 A). Upon stimulation, ROS are generated by NADPH oxidase, which forms a membrane-bound complex, including p22 phox and gp91phox (cytochrome b558) and cytosolic proteins such as $4^{47^{p h o x}}(33,34)$. The complex of gp91 $9{ }^{\text {hhox }}$ and $\mathrm{p} 47^{\text {phox }}$ started to increase $5 \mathrm{~min}$ after LPS treatment, whereas complex formation was inhibited by $\mathrm{CO}$ as well as DPI treatment (Fig. 9 B). Furthermore, superoxide anion production, detected in isolated membrane fractions from LPS-treated macrophages, was inhibited when the cells were also exposed to $\mathrm{CO}$ (Fig. 9 C). Because $\mathrm{CO}$ is known to bind to heme proteins such as hemoglobin (1), we asked whether CO may interact with gp91 phox , a heme protein $(34,35)$. To address this question, we partially purified cytochrome $b 558$ from bovine neutrophils and performed a spectral analysis. An oxidized spectrum was observed with a major peak at $410 \mathrm{~nm}$. Heme proteins show major peak of absorption spectra typically at $400-450 \mathrm{~nm}$ and minor peaks in the range of $500-650 \mathrm{~nm}(35,36)$. After incubation of the extract with sodium dithionite, the major peak shifted to $421 \mathrm{~nm}$, generating distinct difference spectra (Fig. S2, available at http://www.jem.org/cgi/content/full/jem.20060845/DC1). Exposure of $\mathrm{CO}$ to the dithionite-reduced form of cytochrome 6558 extract decreased the absorption peak and shifted the major peak from 421 to $418 \mathrm{~nm}$, generating distinct 
A

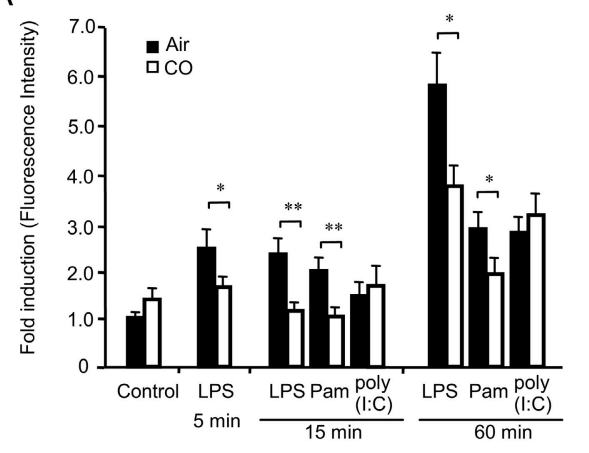

B

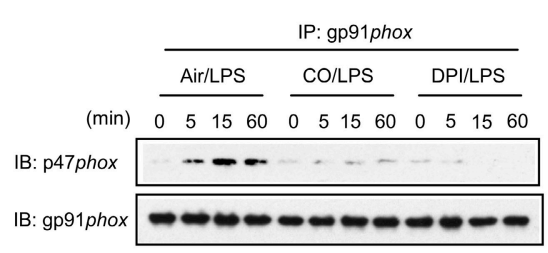

D
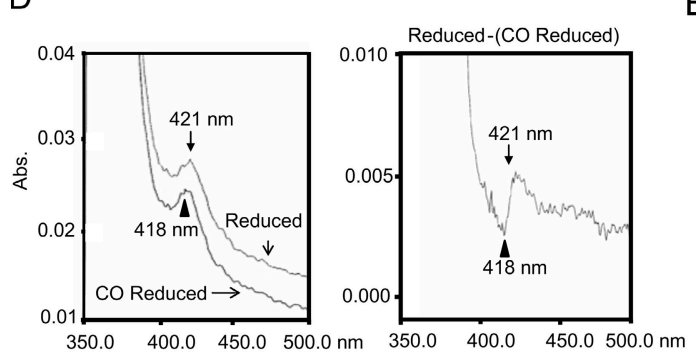

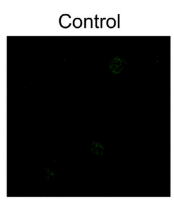

Air/LPS $60 \mathrm{~min}$
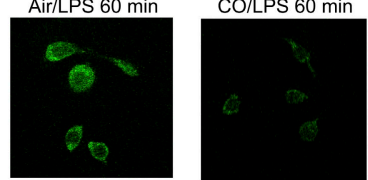

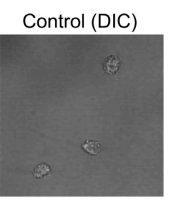

CO/LPS $60 \mathrm{~min}$
C

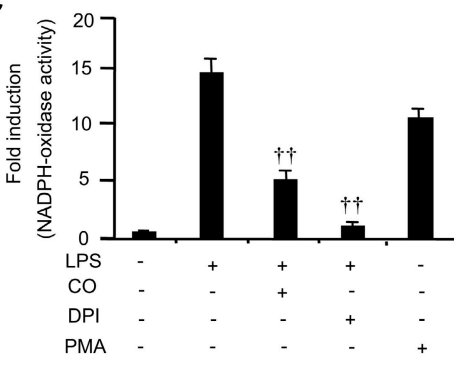

$E$
$\mathrm{F}$

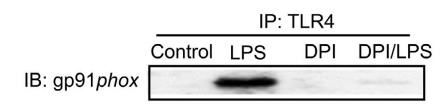

G

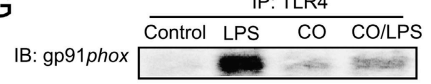

Figure 9. CO inhibits LPS-induced TLR4 trafficking by inhibiting NADPH oxidase activity. (A) RAW 264.7 cells were incubated with $100 \mathrm{ng} / \mathrm{ml} \mathrm{LPS}, 100 \mathrm{ng} / \mathrm{ml} \mathrm{Pam}$, and $20 \mu \mathrm{g} / \mathrm{ml}$ poly $(\mathrm{l}: \mathrm{C})$ in the presence or absence of $\mathrm{CO}$ after preincubation with $10 \mu \mathrm{M}$ CM- $\mathrm{H}_{2}$ DCFDA for $30 \mathrm{~min}$. Fluorescence intensity of the cells was measured as the amount of ROS accumulation (left). Representative images are shown from three independent experiments (right). ${ }^{*}, \mathrm{P}<0.05$ and ${ }^{*}{ }^{*}, \mathrm{P}<0.01$ versus $\mathrm{CO}$ treated cells. (B) RAW 264.7 cells were treated with LPS in the presence or absence of CO or DPI. Interaction of gp91 $1^{\text {phox }}$ and $\mathrm{p} 47^{\text {phox }}$ was analyzed by immunoprecipitation assay. (C) RAW 264.7 cells were treated with LPS for $30 \mathrm{~min}$ in the presence or absence of $\mathrm{CO}$ or DPI. Superoxide production was analyzed by determining the reduction rate of acetylated cytochrome C.,$++ P<0.01$ versus LPS-treated control cell. (D) Cytochrome 6558 fraction was isolated from bovine neutrophils and the spectra of cytochrome
$\mathrm{H}$

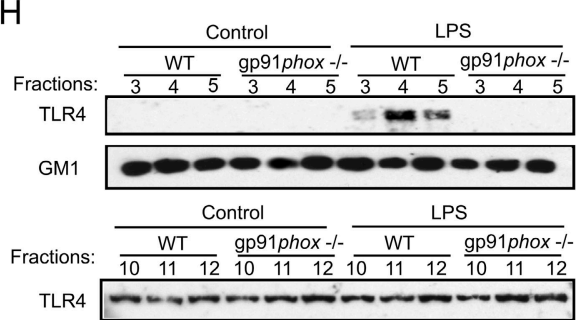

b558 were analyzed. The isolated oxidized cytochrome 6558 was reduced by adding $5 \mathrm{mM}$ of sodium dithionite and $\mathrm{CO}$ was bubbled for $30 \mathrm{~s}$, followed by spectra analysis (left). The spectral difference between the control (Reduced form) and CO-treated sample (CO Reduced) was shown (right). (E) Peritoneal macrophages were isolated from gp91 phox-deficient (gp91phox-/-) mice and wild-type (WT) mice. Cells were exposed to LPS for $1 \mathrm{~h}$ in the presence or absence of CO. TNF- $\alpha$ production in cell media was analyzed by ELISA. + +, $P<0.01$ versus air/LPS (WT). ${ }^{* *}, P<0.01$ versus air/LPS (WT). (F and G) RAW 264.7 cells were stimulated with LPS in the presence or absence of DPI or $\mathrm{CO}$, and the interaction of TLR4 and gp91phox was analyzed using immunoprecipitation assay. $(\mathrm{H})$ Peritoneal macrophages from gp91 ${ }^{\text {phox }}$-deficient and wild-type mice were stimulated with $100 \mathrm{ng} / \mathrm{ml}$ LPS for $5 \mathrm{~min}$. Cell lysates were fractionated to 12 subfractions, followed by immunoblotting for TLR4 and GM1. 
difference spectra (Fig. 9 D). To elucidate the functional role of NADPH oxidase in TLR signaling, peritoneal macrophages from $\mathrm{gp} 91^{\text {phox }}$-deficient $\left(\mathrm{gp} 91^{\text {phox-/-}}\right)$ mice were exposed with LPS in the presence or absence of CO. Cells from gp91phox-/- mice significantly produced less TNF- $\alpha$ in response to LPS than the cells from the wild-type control (37). The effect of CO on LPS-induced TNF- $\alpha$ production was impaired in gp91 phox-deficient cells (Fig. 9 E). In addition, we examined the interaction of TLR 4 and gp91 phox by LPS. TLR 4 interacted with gp9 $91^{\text {phox }}$ in response to LPS treatment, whereas DPI treatment inhibited the interaction (Fig. 9 F). CO inhibited the LPS-induced complex formation of TLR4 and gp91phox (Fig. 9 G). Finally, to confirm if NADPH oxidase is involved in the LPS-induced translocation of TLR 4 to lipid rafts, we isolated lipid rafts from peritoneal macrophages from gp91 phox-1- mice. TLR 4 translocated to lipid rafts $5 \mathrm{~min}$ after LPS treatment in the wild-type cells; however, the translocation of TLR4 by LPS was suppressed in gp $91^{\text {phox }}$-deficient cells (Fig. $9 \mathrm{H}$ ). These results suggest that gp91 phox is involved with LPS-induced translocation of TLR4 to lipid rafts and that the effect of $\mathrm{CO}$ on trafficking to lipid rafts is potentially mediated by the modulation of $\mathrm{gp} 91^{\text {phox }}$ and the suppression of NADPH oxidase activity, leading to the inhibition of trafficking of TLR 4 to lipid rafts.

\section{DISCUSSION}

Although several negative regulators of TLR signaling have been reported (8), there are few reports that the modulation ofTLR trafficking to lipid rafts correlates with the regulation of TLR signaling, and that elucidate the mechanism of trafficking (27). Here we demonstrate that TLRs show differential patterns of trafficking after TLR ligand stimulation, and that NADPH oxidase is critically involved with translocation of TLR 4 to lipid rafts and downstream TLR signaling. Our results showed that TLR 4 translocated to lipid rafts by LPS, whereas TLR3 remained in the intracellular compartment after poly(I:C) treatment. In addition, $\mathrm{CO}$ significantly suppressed LPS-induced ROS generation, resulting in the inhibition of the recruitment of TLR4 to the rafts and of downstream pathways, including activation of transcription factors and cytokine production. In contrast, $\mathrm{CO}$ failed to regulate the TLR 3 signaling pathway. Thus, CO differentially regulated TLR signaling pathways.

CO negatively regulated TLR2, 4, 5, and 9 signaling pathways as revealed by the inhibition of cytokine production and the inactivation of transcription factors (Figs. 3-5). In addition, the effect of $\mathrm{CO}$ was exerted at the initial signaling events, TLR4-MyD88 or TLR4-TRIF complex formation (Fig. 6). In contrast, $\mathrm{CO}$ had no effect on poly(I:C)-induced TLR3 signaling pathways from complex formation of TRIF and TLR 3 to cytokine production (Figs. 3-6), which is consistent with the observation that $\mathrm{HO}-1$-overexpressing cells failed to suppress poly(I:C)-induced cytokine production (unpublished data). Although recent studies show that the cytoplasmic proteins RIG-I and MDA5 have also been identified as double-stranded RNA detectors $(15,38)$, our results demonstrate that TLR3 plays the dominant role in poly(I:C)induced cytokine production at early time points in macrophages (Fig. 3 D; reference 16). It has been shown that several molecules act as negative regulators in multiple TLR signaling pathways and some of them exert their effects on the level of receptor or adaptor proteins (8). ST2 negatively regulates TLR2, 4, and 9, but not TLR3 signaling (39), which is similar with the differential effect of CO. Although ST2 suppresses TLR 4 signaling by sequestration of the adaptor protein MyD88 and Mal, but not TRIF (39), CO inhibited the LPS-induced interaction of TLR 4 and TRIF as well as of TLR 4 and MyD88. Although Triad3A also negatively regulates TLR4- and TLR9-mediated signal activation, it has no effect on the TLR2 signaling pathway (40). Thus, the mechanism of negative regulation by CO on TLR signaling pathways is likely to be independent of the type of adaptor molecules as well as transcription factors, but dependent on the specificity of TLRs.

Our studies have shown that translocation of TLRs to lipid rafts is also dependent on their diversity $(11,12)$. Although IкB kinase $\alpha / \beta$ and IкB- $\alpha$ are recruited to the lipid rafts in B cell signaling (41), our data showed that LPS stimulation increased the trafficking of not only TLR 4 but also other important signaling molecules in TLR signaling pathways to the raft membrane in macrophages (Fig. 7 B). This conclusion is supported by previous findings that MyD88 is translocated from cytosolic fraction to membrane fraction by LPS in RAW 264.7 cells (29). We showed that TRAF-6, a wellknown important molecule in TLR signaling, translocated to the rafts $5 \mathrm{~min}$ after LPS stimulation, whereas TRAF-2 did not (Fig. 7 B). The differential trafficking patterns of TRAF-2 and TRAF-6 may be dependent on the specificity of ligand stimulation. In a similar fashion, CD40 engagement resulted in differential translocation patterns, such that TRAF-2 translocated to lipid rafts but TRAF-6 did not (42). We showed that CpG stimulation translocated TLR9 to membrane rafts (Fig. $7 \mathrm{C}$ ), similar to the previous observation that a small portion of TLR9 becomes cell surface accessible after $\mathrm{CpG}$ treatment (43). Together with previous results on the localization of TLR $9(43,44)$, the recognition of CpG by TLR9 is likely to occur not only in the intracellular compartment but also in lipid rafts where TLR 9 presumably clusters from cytosol after $\mathrm{CpG}$ stimulation in macrophages. Lipid rafts cross-linked with anti-CTx antibody immediately increase intracellular $\mathrm{Ca}^{2+}$, which is up-regulated by ROS stimulation and which is required for the trafficking of molecules from the cytosolic compartment to the plasma membrane $(32,45,46)$. Although cross-linking with anti-CTx causes signaling events analogous to activation of $\mathrm{T}$ cell receptor signaling $(22,23,45)$, the results suggest that crosslinking by anti-CTx at $37^{\circ} \mathrm{C}$ is likely to provoke trafficking of TLR 4 to the crescent-shaped membrane patch similar to biochemically isolated rafts. Although the cross-linking at $37^{\circ} \mathrm{C}$ showed translocation of TLR 4 to the crescent-shaped patched area, TLR3 remained in the intracellular compartment (Fig. S1, A and B). These diverse patterns of TLRs 
trafficking by the cross-linking are very similar to those by TLR ligand stimulation (Fig. 7, A and C). Moreover, the effect of M $\beta C D$ and MDC on poly (I:C)-induced TNF- $\alpha$ production was opposite to the responses to LPS or Pam (Fig. 7, $\mathrm{D}$ and $\mathrm{E}$ ). The signaling events of TLR 3 are unlikely to occur in the raft membrane $(17,24)$, whereas the rafts are involved with the other TLR signaling pathways $(11,12)$.

Despite several results about the involvement of ROS in TLR signaling $(30,31)$, the role of ROS on trafficking to lipid rafts and on TLR signaling is still unclear. ROS such as superoxide or hydrogen peroxide are known to regulate activation of NF- $\mathrm{kB}$ or cytokine production $(30,31)$. We showed that LPS-induced NADPH oxidase-dependent ROS generation is critically involved in the translocation of TLR 4 to lipid rafts and the initiation of the TLR signaling pathway. Furthermore, not only stimulation with hydrogen peroxide but also PMA, a potent NADPH oxidase activator (Fig. 9 C), can recruit TLR 4 to lipid rafts (Fig. 8 E). Powers et al. (32) have reported that oxidative stress induced by hemorrhagic shock recruits TLR 4 to the plasma membrane in macrophages. The present study shows that NADPH oxidase-dependent ROS generation induced by TLR ligand stimulation plays a critical role in the trafficking of TLR to lipid rafts and the initiation of downstream signaling pathways. In addition, the results suggest that the inhibitory effect of $\mathrm{CO}$ on the translocation of TLR 4 to membrane rafts and on TLR signaling is mediated through the inhibition of NADPH oxidase activity. We observed similar differential effects of DPI and CO on TLR ligand-induced $\mathrm{TNF}-\alpha$ production (Figs. $3 \mathrm{~A}$ and $8 \mathrm{~B}$ ). In addition, we showed that $\mathrm{CO}$ significantly inhibited ROS production induced by LPS (47) and Pam, but not by poly(I:C), which is similar to the above data (Figs. $3 \mathrm{~A}$ and $9 \mathrm{~A}$ ). Two integral membrane proteins, gp $91^{\text {phox }}$ and $\mathrm{p} 22^{\text {phox }}$, form a stabilizing complex, termed cytochrome 6558 , and heme incorporation into gp $91^{\text {phox }}$ is essential for the heterodimer formation (34). Recent studies showed that CO modulates the activity of heme proteins such as a potassium channel and soluble guanylate cyclase $(1,35,48)$. Our spectral results also suggest that CO may form a complex with cytochrome 6558 (Fig. 9 D). One of the critical roles of NADPH oxidase in professional immune cells is to generate ROS as a defense against invading microorganisms. It is known that gp91 phox -deficient humans, such as patients with chronic granulomatous disease, lack the ability to produce ROS, including superoxide (34). Our data showed that LPS-induced TNF- $\alpha$ production was significantly suppressed in macrophages from gp91 phox -deficient mice. In addition to this physiological importance of gp91 phox on LPS-induced proinflammatory cytokine production, we demonstrated LPS-induced interaction between gp91 ${ }^{\text {phox }}$ and TLR 4 by using immunoprecipitation analysis (Fig. 9 F). DPI, an NADPH oxidase inhibitor, suppressed this interaction as well as inhibited LPS-induced TLR4 signaling and cytokine production (Fig. 8, A-C). These results confirm a crucial link between gp91 phox and TLR 4 signaling pathways. Consistent with previous results $(47,49)$, we showed that $\mathrm{CO}$ inhibits LPS-induced superoxide generation, associated with NADPH oxidase activation, in the membrane fraction of macrophages (Fig. 9 C). Furthermore, our results indicate that $\mathrm{CO}$ inhibited LPS-induced complex formation of gp91 phox and $\mathrm{p} 47^{\text {phox }}$, which is essential for assembling the active complex of NADPH oxidase (Fig. 9 B). The possible interaction of CO with cytochrome 6558 may inhibit complex formation with cytosolic NADPH oxidase components. We showed that not only inhibition of NADPH oxidase activity but also lack of gp91 $1^{\text {phox }}$ abolished the trafficking of TLR 4 to the rafts by LPS (Figs. $8 \mathrm{D}$ and $9 \mathrm{H}$ ). These results suggest that $\mathrm{CO}$ inhibits LPS-induced translocation of TLR 4 to lipid rafts by inhibiting NADPH oxidase activity. Moreover, our results indicate that $\mathrm{CO}$ is likely to modulate gp91 ${ }^{\text {phox }}$, which is supported by the following observations: CO failed to suppress LPSinduced TNF- $\alpha$ production in gp91 $9{ }^{\text {phox }}$-deficient macrophages; CO inhibited LPS-induced complex formation of gp91 ${ }^{\text {phox }}$ and TLR4; and CO can form a complex with $b 558$ in vitro (Fig. 9, D, E, and G).

Negative regulation of TLR signaling pathways by $\mathrm{CO}$ is likely to be mediated by the modulation of trafficking of TLRs to membrane rafts, and CO inhibits the trafficking by inhibition of NADPH oxidase activity, potentially through gp91 ${ }^{\text {phox }}$. First, CO suppressed TLR 4 signaling, but not TLR3 (Figs. 3-6). Second, LPS stimulation rapidly translocated TLR 4 to lipid rafts, but TLR3 did not translocate to the rafts in response to poly(I:C) as revealed by immunoblotting and immunofluorescence studies (Fig. 7, A-C). Third, CO blocked LPS-induced recruitment of TLR 4 and other signaling molecules to lipid rafts (Fig. 7 B). Finally, CO suppressed LPS-induced ROS production including superoxide production (Fig. 9, A and C), and this effect of CO was impaired in gp91 ${ }^{\text {phox }}$-deficient cells (Fig. 9 E). Thus, ROS generated through NADPH oxidase activation is critically involved in signal transduction of TLRs in lipid rafts.

Recent studies in HO-1-deficient humans and mice provide the strongest evidence that HO-1 is a crucially important molecule in host defense against oxidative stress induced by various stimuli including LPS (2-4). Against invading PAMPs from microorganisms, macrophages dominantly contribute to the production of proinflammatory mediators (50). The high expression of TNF- $\alpha$ in the macrophages of $\mathrm{HO}-1^{-/-}$mice (Fig. 1) and negative regulatory effects of $\mathrm{HO}-1$ on TLR ligand-induced TNF- $\alpha$ production in the macrophages (Fig. 2 A) suggest that $\mathrm{HO}-1$ is likely to be an important molecule in regulating the activation of immune cells. Although biliverdin, the other byproduct of $\mathrm{HO}-1$, also has cytoprotective effects (1), our results showed that scavenging $\mathrm{CO}$ by hemoglobin abolished the effect of HO-1 in TLR signaling (Fig. $2 \mathrm{~B}$ ). Thus, HO-1 has a potent antiinflammatory role in TLR-mediated immune responses, and that role is mainly mediated through $\mathrm{HO}-1$-derived $\mathrm{CO}(5,14)$.

In summary, we have demonstrated that TLR trafficking evoked by ligand stimulation differentially occurred and that HO-1-derived $\mathrm{CO}$ negatively regulated TLR signaling pathways by the inhibition of TLRs trafficking to membrane rafts, resulting in suppression of downstream signaling 
and cytokine production. In addition, $\mathrm{CO}$ inhibited trafficking of TLR by suppressing NADPH oxidase-dependent ROS generation. Because excessive inflammatory mediator production during sepsis causes severe tissue damage or organ dysfunction beyond essential host defense function (51), it is critically important to control ROS production as a key cell signaling activator in the immune system. The present study suggests that $\mathrm{CO}$, a gas molecule produced physiologically in cells, might have a potent role to regulate PAMP-induced proinflammatory cascades by modulating ROS generation, resulting in the suppression of inappropriate hyperreactive immune responses. We have previously reported that the effect of CO on LPS-induced cytokine production is mediated by p38 MAPK (5), and recent results have suggested another mechanism of $\mathrm{CO}$ on the LPS-induced inflammatory response, which is mediated by PPAR- $\gamma$ (52). However, these results do not address the involvement of MAPK and PPAR- $\gamma$ in the trafficking of TLR to lipid rafts. Although further studies are needed to investigate the precise mechanisms of $\mathrm{CO}$ action, our results show that $\mathrm{CO}$ is a novel candidate as a negative regulator in TLR signaling pathways.

\section{MATERIALS AND METHODS}

Cell culture. RAW 264.7 cells and mouse peritoneal macrophages were maintained in DMEM containing 10\% fetal bovine serum and antibiotics (5). For $\mathrm{CO}$ treatment, $\mathrm{CO}$ at a concentration of $1 \%$ corresponding to $10,000 \mathrm{ppm}$ in compressed air was mixed with compressed air containing $5 \% \mathrm{CO}_{2}$ before delivery into the exposure chamber as described previously (5). After $2 \mathrm{~h}$ of pretreatment with either CO (0-500 ppm) or air, LPS (Sigma-Aldrich), peptidoglycan (Fluka), Pam ${ }_{3}$ CSK4 (InvivoGen), poly(I:C) (GE Healthcare), flagellin (InvivoGen), or CpG oligonucleotide was added to the culture media and the culture plates were returned to the chambers.

Transfection. RAW 264.7 cells were stably transfected with a pSFFV/ HO-1 plasmid construct as described previously (5).

Mouse strains. C57BL/6 wild-type mice and gp91 phox -deficient mice (C57BL/6 background) were purchased from The Jackson Laboratory. HO-1-deficient mice were provided by S.-F. Yet (Brigham and Women's Hospital, Boston, MA; reference 53). TLR3-deficient mice were derived as described previously (54). Animals were housed according to guidelines from the American Association for Laboratory Animal Care and Research Protocols and were approved by the Animal Care and Use Committee (University of Pittsburgh School of Medicine).

Sucrose-gradient raft fraction. Sucrose-gradient raft fractions were separated as described previously (55). In brief, cells were lysed in ice-cold MBS buffer $(25 \mathrm{mM}$ MES, pH 6.5, $150 \mathrm{mM} \mathrm{NaCl}, 1 \%$ Triton X-100, $1 \mathrm{mM}$ $\mathrm{Na}_{3} \mathrm{VO}_{4}$, and protease inhibitors). Lysates were adjusted to $4 \mathrm{ml}$ of $40 \%$ sucrose by mixing with $2 \mathrm{ml}$ of $80 \%$ sucrose and overlaid with $4 \mathrm{ml}$ of $35 \%$ sucrose and $4 \mathrm{ml}$ of $5 \%$ sucrose in MBS buffer. Samples were ultracentrifuged at $39,000 \mathrm{rpm}$ for $18 \mathrm{~h}$ and fractionated into 12 subfractions.

Cytokine analysis. Media were analyzed with ELISA kits purchased from R\&D Systems.

RNA quantification. Real-time PCR analysis was performed as described previously (56). mRNA expression was quantified by SYBR Green two-step, real-time RT-PCR for IFN- $\beta$. The sequence of the primer for IFN- $\beta$ is $5^{\prime}$ AGCTCCAAGAAAGGACGAACAT, $3^{\prime}$ GCCCTGTAGGTGA-
GGTTGATCT (18). The expression of each gene was normalized to GAPDH mRNA content and calculated relative to control.

Electrophoretic mobility shift assay and NF- $\kappa B$ transcription factor assay. Nuclei extraction and electrophoretic mobility shift assay was performed as described previously (19). A double-stranded oligonucleotide containing the consensus transcription factor-binding site for NF- $\mathrm{kB}$ was purchased from Promega. p $65 \mathrm{NF}-\mathrm{\kappa B}$ transcriptional activity was also analyzed with ELISA-based kits purchased from Active Motif.

Immunoblotting and Immunoprecipitation. The rabbit anti-TLR4, TRAF-6, TRAF-2, IL-1 receptor-associated kinase 1, CD-14, and MD-2 were purchased from Santa Cruz Biotechnology, Inc. The rabbit anti-p65, total Iк-B, and IRF-3 were purchased from Cell Signaling Technology. The rabbit anti-TRIF and TLR9 were purchased from Abcam. The rabbit antiMyD88 was purchased from Chemicon. The rabbit anti-TLR3 and HO-1 were purchased from StressGen Biotechnologies. The mouse anti-flotillin-1, p47phox and gp91 ${ }^{\text {phox }}$ were purchased from BD Biosciences. CTx B Subunit peroxidase conjugate was purchased from Sigma-Aldrich. Immunoprecipitation and SDS-PAGE was performed as described previously $(55,57)$.

Immunofluorescence and confocal microscopy. After incubation with TLR ligands, the cells were washed with serum-free medium and incubated with $8 \mu \mathrm{g} / \mathrm{ml}$ FITC-conjugated CTx B (FITC-CTx; Sigma-Aldrich) on ice for $10 \mathrm{~min}$. After fixation and permeabilization, cells were stained with the rabbit anti-TLR3 or anti-TLR4 (Santa Cruz Biotechnology, Inc.). After washing, samples were incubated with Alexa 594-coupled secondary antibody for $1 \mathrm{~h}$ (55). For raft-aggregation experiments, cells were incubated with $8 \mu \mathrm{g} / \mathrm{ml}$ FITC-CTx on ice for $10 \mathrm{~min}$, followed by incubation with $4 \mu \mathrm{l} / \mathrm{ml}$ goat anti-CTx (Calbiochem) for $15 \mathrm{~min}$ at 4 or $37^{\circ} \mathrm{C}$ (23). Cells were placed on ice and washed with cold PBS and then fixed, permeabilized, and stained with anti-TLR3 or anti-TLR4, as described above. For analyzing ROS, the cells were preincubated with $10 \mu \mathrm{M} \mathrm{CM}-\mathrm{H}_{2}$ DCFDA (Invitrogen) for $30 \mathrm{~min}$, followed by incubation with TLR ligands (31). Samples were viewed with an Olympus Fluoview 300 Confocal Laser Scanning head with an Olympus IX70 inverted microscope, as described previously (55). Fluorescence intensity of cells exposed with CM- $\mathrm{H}_{2}$ DCFDA was analyzed by Olympus Fluoview (V. 3.1.16) software from Olympus Optical Co.

Immunocytochemistry. Livers and kidneys were fixed, embedded, and serially sectioned $(5 \mu \mathrm{m})$ in toto. Paraffin-embedded tissues were hydrated, retrieved, and immunostained with anti-TNF- $\alpha$ (BD Biosciences) and monoclonal anti-CI:A3-1(RDI) for macrophage staining. Bound primary antibodies were visualized with diaminobenzidine staining by using $\mathrm{ABC}$ kits (Vector Laboratories).

Preparation of membrane fraction and assay of superoxide anion production. Membrane fraction was isolated as described previously (58). The protein $(1 \mathrm{mg} / \mathrm{ml}$ protein) was incubated with $1.2 \mathrm{mg} / \mathrm{ml}$ acetylated cytochrome C, $1 \mathrm{mg} / \mathrm{ml} \mathrm{NADPH}$ in the presence or absence of $1 \mathrm{mg} / \mathrm{ml}$ superoxide dismutase for $20 \mathrm{~min}$ at $37^{\circ} \mathrm{C}$. The reactions were read at $550 \mathrm{~nm}$, subtracting the A550 of the reaction containing superoxide dismutase. The production of superoxide was calculated assuming an extinction coefficient of $21 \mathrm{mM}^{-1} \mathrm{~cm}^{-1}$ for reduced cytochrome $\mathrm{C}$ and normalized for mg protein and reaction time. Values were expressed as fold increase over control value.

Cytochrome b558 isolation and spectral analysis. Fresh bovine peripheral blood was harvested and the neutrophils were isolated by using the erythrocyte-granulocyte fraction. Bovine cytochrome $b 558$ was prepared as described previously (59). Isolated cytochrome 6558 was analyzed on a double beam recording spectrophotometer (Shimadzu UV2501-PC). After determination of oxidized spectra, the sample cuvette was degassed and replaced with an atmosphere of argon. To obtain reduced spectra, the cuvette was injected through the septum with sodium dithionite solution 
(5 mM). To obtain CO spectra, $100 \%$ CO was bubbled into the cuvette through a septum for $30 \mathrm{~s}$. Corresponding difference spectra were digitally generated.

Statistical analysis. We performed statistical analysis by using an unpaired Student's $t$ test. All Data are mean \pm SD from three different experiments. We considered values of $\mathrm{P}<0.05$ to be statistically significant.

Online supplemental material. Fig. S1 shows the immunofluorescence image of TLRs after cross-linking with anti-CTx antibody in macrophages. Fig.S2 shows spectral analysis of cytochrome $b 558$ isolated from bovine neutrophils. The online supplemental material is available at http://www. jem.org/cgi/content/full/jem.20060845/DC1.

We thank S. Li for providing technical information about $\mathrm{CpG}$ oligonucleotide, S.-F. Yet for providing $\mathrm{HO}$-1-deficient mice, J. Peterson for assistance with the spectral analysis, and Emeka Ifedigbo for technical assistance.

A.M.K. Choi was supported by NIH P01HL070807, R01HL055330, R01HL060234, and R01HL079904. H.P. Kim was supported by AHA 0525552U. S.W. Ryter was supported by AHA $0335035 \mathrm{~N}$.

The authors have no conflicting financial interests.

Submitted: 21 April 2006

Accepted: 31 August 2006

\section{REFERENCES}

1. Ryter, S.W., D. Morse, and A.M. Choi. 2004. Carbon monoxide: to boldly go where NO has gone before. Sci. STKE. 2004:RE6.

2. Yachie, A., Y. Niida, T. Wada, N. Igarashi, H. Kaneda, T. Toma, K. Ohta, Y. Kasahara, and S. Koizumi. 1999. Oxidative stress causes enhanced endothelial cell injury in human heme oxygenase-1 deficiency. J. Clin. Invest. 103:129-135.

3. Poss, K.D., and S. Tonegawa. 1997. Reduced stress defense in heme oxygenase 1-deficient cells. Proc. Natl. Acad. Sci. USA. 94:10925-10930.

4. Kawashima, A., Y. Oda, A. Yachie, S. Koizumi, and I. Nakanishi. 2002. Heme oxygenase-1 deficiency: the first autopsy case. Hum. Pathol. $33: 125-130$.

5. Otterbein, L.E., F.H. Bach, J. Alam, M. Soares, H. Tao Lu, M. Wysk, R.J. Davis, R.A. Flavell, and A.M. Choi. 2000. Carbon monoxide has anti-inflammatory effects involving the mitogen-activated protein kinase pathway. Nat. Med. 6:422-428.

6. Morse, D., S.E. Pischke, Z. Zhou, R.J. Davis, R.A. Flavell, T. Loop, S.L. Otterbein, L.E. Otterbein, and A.M. Choi. 2003. Suppression of inflammatory cytokine production by carbon monoxide involves the JNK pathway and AP-1. J. Biol. Chem. 278:36993-36998.

7. Akira, S., and K. Takeda. 2004. Toll-like receptor signalling. Nat. Rev. Immunol. 4:499-511.

8. Liew, F.Y., D. Xu, E.K. Brint, and L.A. O'Neill. 2005. Negative regulation of toll-like receptor-mediated immune responses. Nat. Rev. Immunol. 5:446-458.

9. Dykstra, M., A. Cherukuri, H.W. Sohn, S.J. Tzeng, and S.K. Pierce. 2003. Location is everything: lipid rafts and immune cell signaling. Annu. Rev. Immunol. 21:457-481.

10. Manes, S., G. del Real, and A.C. Martinez. 2003. Pathogens: raft hijackers. Nat. Rev. Immunol. 3:557-568.

11. Triantafilou, M., K. Miyake, D.T. Golenbock, and K. Triantafilou. 2002. Mediators of innate immune recognition of bacteria concentrate in lipid rafts and facilitate lipopolysaccharide-induced cell activation. J. Cell Sci. 115:2603-2611.

12. Soong, G., B. Reddy, S. Sokol, R. Adamo, and A. Prince. 2004. TLR2 is mobilized into an apical lipid raft receptor complex to signal infection in airway epithelial cells. J. Clin. Invest. 113:1482-1489.

13. Chauveau, C., S. Remy, P.J. Royer, M. Hill, S. Tanguy-Royer, F.X. Hubert, L. Tesson, R. Brion, G. Beriou, M. Gregoire, et al. 2005. Heme oxygenase-1 expression inhibits dendritic cell maturation and proinflammatory function but conserves IL-10 expression. Blood. 106:1694-1702.

14. Lee, T.S., and L.Y. Chau. 2002. Heme oxygenase- 1 mediates the antiinflammatory effect of interleukin-10 in mice. Nat. Med. 8:240-246.
15. Meylan, E., and J. Tschopp. 2006. Toll-like receptors and RNA helicases: two parallel ways to trigger antiviral responses. Mol. Cell. 22:561-569.

16. Alexopoulou, L., A.C. Holt, R. Medzhitov, and R.A. Flavell. 2001. Recognition of double-stranded RNA and activation of NF-kappaB by Toll-like receptor 3. Nature. 413:732-738.

17. Kawai, T., and S. Akira. 2006. Innate immune recognition of viral infection. Nat. Immunol. 7:131-137.

18. Doyle, S., S. Vaidya, R. O'Connell, H. Dadgostar, P. Dempsey, T. Wu, G. Rao, R. Sun, M. Haberland, R. Modlin, and G. Cheng. 2002. IRF3 mediates a TLR3/TLR4-specific antiviral gene program. Immunity. 17:251-263.

19. Sarady, J.K., S.L. Otterbein, F. Liu, L.E. Otterbein, and A.M. Choi 2002. Carbon monoxide modulates endotoxin-induced production of granulocyte macrophage colony-stimulating factor in macrophages. Am. J. Respir. Cell Mol. Biol. 27:739-745.

20. Medvedev, A.E., A. Lentschat, L.M. Wahl, D.T. Golenbock, and S.N. Vogel. 2002. Dysregulation of LPS-induced Toll-like receptor 4MyD88 complex formation and IL-1 receptor-associated kinase 1 activation in endotoxin-tolerant cells. J. Immunol. 169:5209-5216.

21. Hornef, M.W., B.H. Normark, A. Vandewalle, and S. Normark. 2003. Intracellular recognition of lipopolysaccharide by Toll-like receptor 4 in intestinal epithelial cells. J. Exp. Med. 198:1225-1235.

22. Bi, K., Y. Tanaka, N. Coudronniere, K. Sugie, S. Hong, M.J. van Stipdonk, and A. Altman. 2001. Antigen-induced translocation of PKC-theta to membrane rafts is required for T cell activation. Nat. Immunol. 2:556-563.

23. Gaide, O., B. Favier, D.F. Legler, D. Bonnet, B. Brissoni, S. Valitutti, C. Bron, J. Tschopp, and M. Thome. 2002. CARMA1 is a critical lipid raft-associated regulator of TCR-induced NF-kappa B activation. Nat. Immunol. 3:836-843.

24. Matsumoto, M., K. Funami, M. Tanabe, H. Oshiumi, M. Shingai, Y. Seto, A. Yamamoto, and T. Seya. 2003. Subcellular localization of Tolllike receptor 3 in human dendritic cells. J. Immunol. 171:3154-3162.

25. Harder, T., P. Scheiffele, P. Verkade, and K. Simons. 1998. Lipid domain structure of the plasma membrane revealed by patching of membrane components. J. Cell Biol. 141:929-942.

26. Fessler, M.B., P.G. Arndt, S.C. Frasch, J.G. Lieber, C.A. Johnson, R.C. Murphy, J.A. Nick, D.L. Bratton, K.C. Malcolm, and G.S. Worthen. 2004. Lipid rafts regulate lipopolysaccharide-induced activation of Cdc42 and inflammatory functions of the human neutrophil. J. Biol. Chem. 279:39989-39998.

27. Triantafilou, M., K. Brandenburg, S. Kusumoto, K. Fukase, A. Mackie, U. Seydel, and K. Triantafilou. 2004. Combinational clustering of receptors following stimulation by bacterial products determines lipopolysaccharide responses. Biochem. J. 381:527-536.

28. Dai, Q., J. Zhang, and S.B. Pruett. 2005. Ethanol alters cellular activation and CD14 partitioning in lipid rafts. Biochem. Biophys. Res. Commun. 332:37-42.

29. Ahmad-Nejad, P., H. Hacker, M. Rutz, S. Bauer, R.M. Vabulas, and H. Wagner. 2002. Bacterial CpG-DNA and lipopolysaccharides activate Toll-like receptors at distinct cellular compartments. Eur. J. Immunol. 32:1958-1968.

30. Park, H.S., H.Y. Jung, E.Y. Park, J. Kim, W.J. Lee, and Y.S. Bae. 2004. Cutting edge: direct interaction of TLR 4 with $\mathrm{NAD}(\mathrm{P}) \mathrm{H}$ oxidase 4 isozyme is essential for lipopolysaccharide-induced production of reactive oxygen species and activation of NF-kappa B. J. Immunol. 173:3589-3593.

31. Matsuzawa, A., K. Saegusa, T. Noguchi, C. Sadamitsu, H. Nishitoh, S Nagai, S. Koyasu, K. Matsumoto, K. Takeda, and H. Ichijo. 2005. ROSdependent activation of the TRAF6-ASK1-p38 pathway is selectively required for TLR4-mediated innate immunity. Nat. Immunol. 6:587-592.

32. Powers, K.A., K. Szaszi, R.G. Khadaroo, P.S. Tawadros, J.C. Marshall, A. Kapus, and O.D. Rotstein. 2006. Oxidative stress generated by hemorrhagic shock recruits Toll-like receptor 4 to the plasma membrane in macrophages. J. Exp. Med. 203:1951-1961.

33. Li, J.M., and A.M. Shah. 2002. Intracellular localization and preassembly of the NADPH oxidase complex in cultured endothelial cells J. Biol. Chem. 277:19952-19960.

34. Sumimoto, H., K. Miyano, and R. Takeya. 2005. Molecular composition and regulation of the Nox family $\mathrm{NAD}(\mathrm{P}) \mathrm{H}$ oxidases. Biochem. Biophys. Res. Commun. 338:677-686. 
35. Taille, C., J. El-Benna, S. Lanone, J. Boczkowski, and R. Motterlini. 2005. Mitochondrial respiratory chain and NAD(P)H oxidase are targets for the antiproliferative effect of carbon monoxide in human airway smooth muscle. J. Biol. Chem. 280:25350-25360.

36. Reinking, J., M.M. Lam, K. Pardee, H.M. Sampson, S. Liu, P. Yang, S. Williams, W. White, G. Lajoie, A. Edwards, and H.M. Krause. 2005 The Drosophila nuclear receptor e75 contains heme and is gas responsive. Cell. 122:195-207.

37. Peng, T., X. Lu, and Q. Feng. 2005. Pivotal role of gp91phox-containing NADH oxidase in lipopolysaccharide-induced tumor necrosis factoralpha expression and myocardial depression. Circulation. 111:1637-1644.

38. Kato, H., O. Takeuchi, S. Sato, M. Yoneyama, M. Yamamoto, K. Matsui, S. Uematsu, A. Jung, T. Kawai, K.J. Ishii, et al. 2006. Differential roles of MDA5 and RIG-I helicases in the recognition of RNA viruses. Nature. 441:101-105.

39. Brint, E.K., D. Xu, H. Liu, A. Dunne, A.N. McKenzie, L.A. O’Neill, and F.Y. Liew. 2004. ST2 is an inhibitor of interleukin 1 receptor and Toll-like receptor 4 signaling and maintains endotoxin tolerance. Nat. Immunol. 5:373-379.

40. Chuang, T.H., and R.J. Ulevitch. 2004. Triad3A, an E3 ubiquitinprotein ligase regulating Toll-like receptors. Nat. Immunol. 5:495-502.

41. Su, T.T., B. Guo, Y. Kawakami, K. Sommer, K. Chae, L.A. Humphries, R.M. Kato, S. Kang, L. Patrone, R. Wall, et al. 2002. PKC-beta controls I kappa B kinase lipid raft recruitment and activation in response to BCR signaling. Nat. Immunol. 3:780-786.

42. Arron, J.R., Y. Pewzner-Jung, M.C. Walsh, T. Kobayashi, and Y. Choi. 2002. Regulation of the subcellular localization of tumor necrosis factor receptor-associated factor (TRAF) 2 by TRAF1 reveals mechanisms of TRAF2 signaling. J. Exp. Med. 196:923-934.

43. Latz, E., A. Schoenemeyer, A. Visintin, K.A. Fitzgerald, B.G. Monks, C.F. Knetter, E. Lien, N.J. Nilsen, T. Espevik, and D.T. Golenbock. 2004. TLR9 signals after translocating from the ER to CpG DNA in the lysosome. Nat. Immunol. 5:190-198.

44. Leifer, C.A., M.N. Kennedy, A. Mazzoni, C. Lee, M.J. Kruhlak, and D.M. Segal. 2004. TLR9 is localized in the endoplasmic reticulum prior to stimulation. J. Immunol. 173:1179-1183.

45. Janes, P.W., S.C. Ley, and A.I. Magee. 1999. Aggregation of lipid rafts accompanies signaling via the $\mathrm{T}$ cell antigen receptor. J. Cell Biol. 147:447-461.

46. Qin, S., Y. Minami, M. Hibi, T. Kurosaki, and H. Yamamura. 1997. Syk-dependent and -independent signaling cascades in B cells elicited by osmotic and oxidative stress. J. Biol. Chem. 272:2098-2103.

47. Srisook, K., S.S. Han, H.S. Choi, M.H. Li, H. Ueda, C. Kim, and Y.N. Cha. 2006. CO from enhanced $\mathrm{HO}$ activity or from CORM-2 inhibits both $\mathrm{O} 2-$ and NO production and downregulates $\mathrm{HO}-1$ expression in LPS-stimulated macrophages. Biochem. Pharmacol. 71:307-318.
48. Jaggar, J.H., A. Li, H. Parfenova, J. Liu, E.S. Umstot, A.M. Dopico, and C.W. Leffler. 2005. Heme is a carbon monoxide receptor for large-conductance $\mathrm{Ca} 2+$-activated $\mathrm{K}+$ channels. Circ. Res. 97:805-812.

49. Taille, C., J. El-Benna, S. Lanone, M.C. Dang, E. Ogier-Denis, M. Aubier, and J. Boczkowski. 2004. Induction of heme oxygenase-1 inhibits $\mathrm{NAD}(\mathrm{P}) \mathrm{H}$ oxidase activity by down-regulating cytochrome b558 expression via the reduction of heme availability. J. Biol. Chem. 279:28681-28688.

50. Jenner, R.G., and R.A. Young. 2005. Insights into host responses against pathogens from transcriptional profiling. Nat. Rev. Microbiol. 3:281-294.

51. Riedemann, N.C., R.F. Guo, and P.A. Ward. 2003. Novel strategies for the treatment of sepsis. Nat. Med. 9:517-524.

52. Bilban, M., F.H. Bach, S.L. Otterbein, E. Ifedigbo, J. de Costa d'Avila, H. Esterbauer, B.Y. Chin, A. Usheva, S.C. Robson, O. Wagner, and L.E. Otterbein. 2006. Carbon monoxide orchestrates a protective response through PPARgamma. Immunity. 24:601-610.

53. Yet, S.F., M.A. Perrella, M.D. Layne, C.M. Hsieh, K. Maemura, L. Kobzik, P. Wiesel, H. Christou, S. Kourembanas, and M.E. Lee. 1999. Hypoxia induces severe right ventricular dilatation and infarction in heme oxygenase-1 null mice. J. Clin. Invest. 103:R23-R29.

54. Rudd, B.D., J.J. Smit, R.A. Flavell, L. Alexopoulou, M.A. Schaller, A. Gruber, A.A. Berlin, and N.W. Lukacs. 2006. Deletion of TLR3 alters the pulmonary immune environment and mucus production during respiratory syncytial virus infection. J. Immunol. 176:1937-1942.

55. Kim, H.P., X. Wang, F. Galbiati, S.W. Ryter, and A.M. Choi. 2004 Caveolae compartmentalization of heme oxygenase-1 in endothelial cells. FASEB J. 18:1080-1089.

56. Nakao, A., K. Kimizuka, D.B. Stolz, J.S. Neto, T. Kaizu, A.M. Choi, T. Uchiyama, B.S. Zuckerbraun, M.A. Nalesnik, L.E. Otterbein, and N. Murase. 2003. Carbon monoxide inhalation protects rat intestinal grafts from ischemia/reperfusion injury. Am. J. Pathol. 163:1587-1598

57. Wang, X., Y. Wang, J. Zhang, H.P. Kim, S.W. Ryter, and A.M Choi. 2005. FLIP protects against hypoxia/reoxygenation-induced endothelial cell apoptosis by inhibiting Bax activation. Mol. Cell. Biol. 25:4742-4751.

58. Sekhar, K.R., P.A. Crooks, V.N. Sonar, D.B. Friedman, J.Y. Chan, M.J. Meredith, J.H. Starnes, K.R. Kelton, S.R. Summar, S. Sasi, and M.L. Freeman. 2003. NADPH oxidase activity is essential for Keap1/ Nrf2-mediated induction of GCLC in response to 2-indol-3-yl-methylenequinuclidin-3-ols. Cancer Res. 63:5636-5645.

59. Quinn, M.T., C.A. Parkos, and A.J. Jesaitis. 1995. Purification of human neutrophil NADPH oxidase cytochrome b-558 and association with Rap 1A. Methods Enzymol. 255:476-487. 